\title{
Can domperidone decrease transit time of pediatric video capsule endoscopy? A randomized controlled trial
}

\author{
Jie $\mathbf{W u}^{\#}$, Ziqing Ye", Aijuan Xue, Ying Huang \\ Department of Gastroenterology, Children's Hospital of Fudan University, Shanghai, China \\ Contributions: (I) Conception and design: J Wu, Z Ye, Y Huang; (II) Administrative support: J Wu, Y Huang; (III) Provision of study materials or \\ patients: J Wu; (IV) Collection and assembly of data: J Wu, Z Ye; (V) Data analysis and interpretation: A Xue; (VI) Manuscript writing: All authors; \\ (VII) Final approval of manuscript: All authors. \\ \#These authors contributed equally to this work. \\ Correspondence to: Ying Huang, MD, PhD. Department of Gastroenterology, Children's Hospital of Fudan University, 399 Wanyuan Road, Shanghai \\ 201102, China. Email: yhuang815@163.com.
}

\begin{abstract}
Background: The complete examination rate of video capsule endoscopy can be increased by reduced gastric transit time (GTT) and or small bowel transit time (SBTT). This study aims to examine whether the prokinetic domperidone reduces GTT and/or SBTT in pediatric patients undergoing video capsule endoscopy (VCE).
\end{abstract}

Methods: We performed a single-center randomized controlled trial $(n=200)$ to evaluate the effect of domperidone on GTT and SBTT among pediatric patients in a tertiary university-affiliated hospital for children. We explored whether patients randomized to domperidone had increased GTT, SBTT (primary outcomes) or higher complete examination rate (secondary outcome). The safety outcomes were the adverse effects in the domperidone group. This study was registered on ClinicalTrials.gov (NCT03662113).

Results: Demographic features including gender and age were similar between the 100 patients of the domperidone group and the 100 patients of the control group. The median GTT was 67.5 minutes (44.8$117.5)$ in the domperidone group and 80.0 minutes (42.0-128.0) in the control group, while the median SBTT was 317 minutes (231-436) and 323 minutes (225-426), respectively. There were no significant differences in GTT $(\mathrm{P}=0.49)$ and SBTT $(\mathrm{P}=0.52)$ between the two groups. The complete examination rate was $97 \%$ and $98 \%$ in the domperidone and control groups, respectively $(\mathrm{P}=1.00)$.

Conclusions: Domperidone shows no effect on GTT, SBTT and complete examination rate in pediatric patients receiving VCE.

Keywords: Capsule endoscopy; domperidone; gastric transit time; pediatric; small bowel transit time

Submitted Aug 28, 2020. Accepted for publication Dec 26, 2020.

doi: $10.21037 /$ tp-20-273

View this article at: http://dx.doi.org/10.21037/tp-20-273

\section{Introduction}

Video capsule endoscopy (VCE) is a noninvasive modality in pediatrics to assess small bowel mucosa without anesthesia. VCE has been approved for children older than 2 years of age in 2009 (1). However, limited battery life can lead to incomplete visualization of the small bowel (2). Reducing gastric transit time (GTT), small bowel transit time (SBTT) and maintaining diagnostic yield may enhance complete examination rate (CER) (3). Prokinetics can accelerate gastric emptying and thus potentially reduce GTT and SBTT (4).

Domperidone is a antidopaminergic agent that facilitates gastric emptying (5), and is now widely used for nausea and vomiting (6). The role of antidopaminergic agents in patients receiving VCE has been controversial according to the European Society of Gastrointestinal Endoscopy technical review (7). However, there is no clinical evidence to support the use of prokinetics to improve completion rate 
or SBTT according to the NASPGHAN capsule endoscopy clinical report (1). Recent joint recommendations of the North American society for pediatric gastroenterology, hepatology and nutrition, as well as that of the European society for pediatric gastroenterology, hepatology and nutrition did not suggest using domperidone in pediatric gastroesophageal reflux (5).

Several studies evaluated the effect laxatives, prokinetics, and/or simethicone to improve diagnostic yield, visualization, and completion rate $(8,9)$. However, the results remain conflicting. The routine use of prokinetics before performing VCE was not recommended by the North American Society for Pediatric Gastroenterology, Hepatology and Nutrition (1).

Domperidone is an anti-dopaminergic agent free of extrapyramidal adverse effects, due to its lack of ability to cross the blood-brain barrier (10). A retrospective study showed that domperidone significantly increases completion rate of VCE in adults (10). The effect of domperidone used pre-VCE has not been evaluated in randomized controlled trials among pediatric patients. Thus, the aim of this study was to examine the impact of domperidone on GTT, SBTT and CER in in children and adolescents undergoing VCE.

We present the results in accordance with the CONSORT reporting checklist (available at http://dx.doi.org/10.21037/ tp-20-273).

\section{Methods}

\section{Study design, patient cohort and randomization}

This study was conducted as a single-center, parallel, randomized controlled trial in an university hospital for children between $1^{\text {st }}$, November 2017 and $1^{\text {st }}$, November 2018. Approval for this study was obtained from the Ethical Committee of Children's Hospital, Fudan University (approval number: 2018[54]). Signed informed consent was obtained from the parents of the patients. The study conformed to the provisions of the Declaration of Helsinki (as revised in 2013). This study was retrospectively registered on 7 September 2018 on ClinicalTrials.gov (NCT03662113). Pediatric patients older than 3 years undergoing VCE were eligible for recruitment. Indications for VCE included anemia, obscure gastrointestinal bleeding, Crohn's disease and recurrent abdominal pain of unclear etiology. Patients were excluded on the following criteria: age less than 3 years, whom with history of partial or intermittent small bowel obstruction, and esophageal stricture. Patients were randomized without restriction via concealed allocation to the two groups by a computer-generated random sequence generator prior to the procedure by a nurse assistant. The study investigators were blinded to the randomization.

\section{Procedures}

VCEs were performed using a OMOM capsule CE2012 (Jinshan Science \& Technology, Chongqing, China). Written informed consents were obtained from parents or guardians of all patients before procedure. Participants were randomly assigned to domperidone group and the control group. Both groups were given a clear liquid diet one day prior to VCE and were fast after midnight. The domperidone group received domperidone directly before VCE. Should the capsule remain in the stomach 2.5 hours post ingestion, a gastroscopy would be performed to deliver it into the duodenum. Any participant requiring gastroscopy-assisted delivery of the capsule into the duodenum had their GTT time excluded in the study. The allocation ratio was set as 1:1.

\section{Data collection}

Demographic information, including sex and age, indications for VCE and medical history of the participants were recorded.

\section{Outcomes}

Results of VCEs were reviewed by a nurse specialist and a consultant pediatric gastroenterologist. They were both blinded to participant status. The time of the first gastric image, first duodenal image and first cecal image were recorded in minutes. GTT was defined as time of first duodenal image minus the time of the first gastric image. SBTT was defined as time of first cecal image minus the first duodenal image. Primary outcomes included GTT and SBTT. Complete examination was defined by presence of cecum image at the completion of the recording, which was defined as secondary outcome. Outcomes were analyzed to evaluate whether domperidone can decrease GTT and SBTT, and improve CER. The safety outcomes were the adverse effect in the domperidone group.

\section{Sample size calculation}

To determine the sample size for the trial, a significance level of 0.05 was chosen. Based on the previous study and 
Table 1 Demographic features of patients undergoing VCE

\begin{tabular}{lcc}
\hline Variables & Domperidone $(\mathrm{n}=100)$ & Control $(\mathrm{n}=100)$ \\
\hline Male $(\mathrm{n})$ & 63 & 62 \\
Age (year) & $10.1 \pm 3.4$ & $10.7 \pm 3.6$ \\
Indications for VCE & & \\
Abdominal pain & 47 & 45 \\
IBD & 19 & 20 \\
Chronic diarrhea & 6 & 8 \\
GIB & 15 & 14 \\
Anemia & 2 & 1 \\
Other & 11 & 12 \\
\hline
\end{tabular}

GIB, gastrointestinal bleeding; IBD, inflammatory bowel disease; VCE, video capsule endoscopy.

Table 2 Primary and secondary outcomes

\begin{tabular}{lccc}
\hline Variables & Domperidone $(\mathrm{n}=100)$ & Control $(\mathrm{n}=100)$ & $\mathrm{P}$ value \\
\hline GTT (minutes) & $67.5(44.8-117.5)$ & $80.0(42.0-128.0)$ & 0.48 \\
SBTT (minutes) & $317(231-436)$ & $323(225-426)$ & 0.52 \\
CER (\%) & $97 \%$ & $98 \%$ & 1.00 \\
\hline
\end{tabular}

CER, complete examination rate; GTT, gastric transit time; SBTT, small bowel transit time.

Table 3 Findings of VCE among patients

\begin{tabular}{lccc}
\hline Results & $\begin{array}{c}\text { Domperidone } \\
(\mathrm{n}=100)\end{array}$ & $\begin{array}{c}\text { Control } \\
(\mathrm{n}=100)\end{array}$ & P value \\
\hline Non-clinically significant & 59 & 54 & 0.48 \\
Polyps & 1 & 1 & \\
Ulcers & 34 & 38 & \\
Diverticulum & 1 & 2 & \\
Strictures & 2 & 2 & \\
Angiodysplasias & 2 & 0 & \\
Other & 1 & 3 & \\
\hline
\end{tabular}

a power of $80 \%$, and an expected difference in SBTT of $20 \%$ between the two groups, a total of 83 participants are required in the each group (4). Adjusting for a drop-out rate of $10 \%$ in each group, 92 participants were required in each group. Therefore, we decided to include 100 participants in each group.

\section{Statistical analysis}

Continuous data are reported as mean and standard deviation or median and interquartile range where appropriate. Categorical data are reported as percentages. Chi square test and Fisher's exact test was used to compare the categorical variables. Two sample $t$-test and Mann-Whitney $\mathrm{U}$ test were used to compare the continuous variables. Statistical analyses were performed using SPSS 24.0 (SPSS, Inc., Chicago, IL, USA). A two-tailed $\mathrm{P}$ value $<0.05$ was considered statistically significant.

\section{Results}

There were 125/200 (62.5\%) males among all participants. Between $1^{\text {st }}$, November 2017 and $1^{\text {st }}$, November 2018, we included 100 subjects in the domperidone group and 100 subjects in the control group, respectively. The average age was $10.1 \pm 3.4$ years in the domperidone group and $10.7 \pm 3.6$ years in the control group, respectively $(\mathrm{P}=0.21)$. There was no statistically significant difference in age and sex between two groups.

The most common indications for VCE was investigations for gastrointestinal bleeding, recurrent abdominal pain, and inflammatory bowel disease. Detailed indications are listed in Table 1.

Outcomes are shown in Table 2. Two patients from the control group and three from the domperidone group did not complete examination, and were thus excluded from SBTT analysis. Three patients from the control group and another three from the domperidone group required gastroscopy-assisted delivery of the capsule, and were excluded from the GTT analysis. Median GTT was 67.5 minutes (44.8-117.5) in the domperidone group and 80.0 minutes (42.0-128.0) in the control group. The median SBTT was 317 minutes (231-436) and 323 minutes (225$426)$, respectively. Three patients $(3.0 \%)$ in the domperidone group and three patients $(3.0 \%)$ in the control group required gastroscopy-assisted capsule delivery from oral cavity to the duodenum, respectively. Clinically significant findings of VCE were identified in $41 \%$ of the domperidone group and $46 \%$ of the control group $(\mathrm{P}=0.48)$. Detailed results are shown in Table 3. None of the subjects reported any adverse effect.

\section{Discussion}

To our knowledge, this is the first randomized controlled 
trial evaluating the effect of domperidone on VCE transit time among children. In our study, domperidone reduced GTT and SBTT of VCE. However, this effect was not significant. Domperidone did not improve complete examination rate of children receiving VCE. The effect of domperidone could not be proven, possibly due to sample size. Another retrospective study showed that higher CR was achieved when domperidone was used with certain kind of VCE (PillCamSB; Given Imaging Ltd.) (10). Therefore, we suspect that the effect of domperidone might be affected by the size, weight and center of gravity of VCE models.

A meta-analysis indicated that prokinetics including erythromycin and metoclopramide can improve completion rate in VCE (11). A recent retrospective study showed that domperidone prolonged oral to duodenal transit time in adults receiving VCE (4). However, the methodologies and study populations were different from our study. Other prokinetics have also been studied. In a randomized, prospective and controlled study, mosapride citrate was shown to reduce GTT and improve complete examination rate in adults (12). Erythromycin has also been tested, among which conflicting results were shown. Several studies showed that oral erythromycin significantly reduced GTT (13-15), while another study revealed that erythromycin failed to increase CER (16).

Due to safety concerns, domperidone is currently not available in the United States, while it remains widely used for nausea and vomiting both in Europe and China $(4,17,18)$. There are very few published studies of prokinetic effects of domperidone in children. Nevertheless, a very recent randomized and controlled study showed that domperidone may be a safe and effective therapeutic for remission of symptoms in children with abdominal pain predominant functional gastrointestinal disorders (19). Domperidone has also been used for patients with gastroparesis $(20,21)$, and have proved to improve success rate of enteral nutrition in the intensive care unit $(18,22)$.

There are certain limitations when interpreting this study. This was a single-center study. Patients were enrolled for VCE due to various real-world indications. However, our protocol was reflective of real-life clinical practice. Also, patients were not standardized to age (23).

Our study showed that domperidone failed to increase the complete examination rate of VCE. However, studies also showed that complete examination rate did not equal diagnostic yield, and there is a positive correlation between diagnostic yield and SBTT (24-26).

\section{Conclusions}

In conclusion, domperidone does not reduce GTT, SBTT or improve completion rate among pediatric patients receiving VCE.

\section{Acknowledgments}

We express our gratitude to all the patients and families who participated in the study. We would like to acknowledge Dr. Mushuang Hu for the help in editing the manuscript. Funding: None.

\section{Footnote}

Reporting Checklist: The authors have completed the CONSORT reporting checklist. Available at http://dx.doi. org/10.21037/tp-20-273

Data Sharing Statement: Available at http://dx.doi. org/10.21037/tp-20-273

Conflicts of Interest: All authors have completed the ICMJE uniform disclosure form (available at http://dx.doi. org/10.21037/tp-20-273). The authors have no conflicts of interest to declare.

Ethics Statement: The authors are accountable for all aspects of the work in ensuring that questions related to the accuracy or integrity of any part of the work are appropriately investigated and resolved. Signed informed consent was obtained from the parents of the patients. Ethical approval was obtained from the Ethical Committee of Children's Hospital of Fudan University \{approval number: 2018[54]\}. The study conformed to the provisions of the Declaration of Helsinki (as revised in 2013).

Open Access Statement: This is an Open Access article distributed in accordance with the Creative Commons Attribution-NonCommercial-NoDerivs 4.0 International License (CC BY-NC-ND 4.0), which permits the noncommercial replication and distribution of the article with the strict proviso that no changes or edits are made and the original work is properly cited (including links to both the formal publication through the relevant DOI and the license). See: https://creativecommons.org/licenses/by-nc-nd/4.0/. 


\section{References}

1. Friedlander JA, Liu QY, Sahn B, et al. NASPGHAN Capsule Endoscopy Clinical Report. J Pediatr Gastroenterol Nutr 2017;64:485-94.

2. Ou G, Shahidi N, Galorport C, et al. Effect of longer battery life on small bowel capsule endoscopy. World J Gastroenterol 2015;21:2677-82.

3. Prichard D, Ou G, Galorport C, et al. Sham Feeding with Bacon Does Not Alter Transit Time or Complete Examination Rate During Small Bowel Capsule Endoscopy. Dig Dis Sci 2018;63:422-8.

4. Mcfarlane M, Liu B, Nwokolo C. Domperidone prolongs oral to duodenal transit time in video capsule endoscopy. Eur J Clin Pharmacol 2018;74:521-4.

5. Rosen R, Vandenplas Y, Singendonk M, et al. Pediatric Gastroesophageal Reflux Clinical Practice Guidelines: Joint Recommendations of the North American Society for Pediatric Gastroenterology, Hepatology, and Nutrition and the European Society for Pediatric Gastroenterology, Hepatology, and Nutrition. J Pediatr Gastroenterol Nutr 2018;66:516-54.

6. Romano C, Dipasquale V, Scarpignato C. Antiemetic Drug Use in Children: What the Clinician Needs to Know. J Pediatr Gastroenterol Nutr 2019;68:466-71.

7. Rondonotti E, Spada C, Adler S, et al. Small-bowel capsule endoscopy and device-assisted enteroscopy for diagnosis and treatment of small-bowel disorders: European Society of Gastrointestinal Endoscopy (ESGE) Technical Review. Endoscopy 2018;50:423-46.

8. Postgate A, Tekkis P, Patterson N, et al. Are bowel purgatives and prokinetics useful for small-bowel capsule endoscopy? A prospective randomized controlled study. Gastrointest Endosc 2009;69:1120-8.

9. Caddy GR, Moran L, Chong AK, et al. The effect of erythromycin on video capsule endoscopy intestinal-transit time. Gastrointest Endosc 2006;63:262-6.

10. Koulaouzidis A, Dimitriadis S, Douglas S, et al. The use of domperidone increases the completion rate of small bowel capsule endoscopy: does this come at the expense of diagnostic yield? J Clin Gastroenterol 2015;49:395400 .

11. Koulaouzidis A, Giannakou A, Yung DE, et al. Do prokinetics influence the completion rate in small-bowel capsule endoscopy? A systematic review and meta-analysis. Curr Med Res Opin 2013;29:1171-85.

12. Wei W, Ge ZZ, Lu H, et al. Effect of mosapride on gastrointestinal transit time and diagnostic yield of capsule endoscopy. J Gastroenterol Hepatol 2007;22:1605-8.

13. Leung WK, Chan FK, Fung SS, et al. Effect of oral erythromycin on gastric and small bowel transit time of capsule endoscopy. World J Gastroenterol 2005;11:4865-8.

14. Fireman Z, Paz D, Kopelman Y. Capsule endoscopy: improving transit time and image view. World J Gastroenterol 2005;11:5863-6.

15. Rozov-Ung I, Mreyoud A, Moore J, et al. Detection of drug effects on gastric emptying and contractility using a wireless motility capsule. BMC Gastroenterol 2014;14:2.

16. Niv E, Bonger I, Barkay O, et al. Effect of erythromycin on image quality and transit time of capsule endoscopy: a two-center study. World J Gastroenterol 2008;14:2561-5.

17. Mt-Isa S, Tomlin S, Sutcliffe A, et al. Prokinetics prescribing in paediatrics: evidence on cisapride, domperidone, and metoclopramide. J Pediatr Gastroenterol Nutr 2015;60:508-14.

18. Hu B, Ye H, Sun C, et al. Metoclopramide or domperidone improves post-pyloric placement of spiral nasojejunal tubes in critically ill patients: a prospective, multicenter, open-label, randomized, controlled clinical trial. Crit Care 2015;19:61.

19. Karunanayake A, Devanarayana NM, de Silva A, et al. Randomized Controlled Clinical Trial on Value of Domperidone in Functional Abdominal Pain in Children. J Pediatr Gastroenterol Nutr 2018;66:725-31.

20. Parkman HP, Yamada G, Van Natta ML, et al. Ethnic, Racial, and Sex Differences in Etiology, Symptoms, Treatment, and Symptom Outcomes of Patients With Gastroparesis. Clin Gastroenterol Hepatol 2019;17:1489-1499.e8.

21. Ramprasad C, Douglas JY, Moshiree B. Parkinson's Disease and Current Treatments for Its Gastrointestinal Neurogastromotility Effects. Curr Treat Options Gastroenterol 2018;16:489-510.

22. Lewis K, Alqahtani Z, McIntyre L, et al. The efficacy and safety of prokinetic agents in critically ill patients receiving enteral nutrition: a systematic review and meta-analysis of randomized trials. Crit Care 2016;20:259.

23. Shibuya T, Mori H, Takeda T, et al. The relationship between physical activity level and completion rate of small bowel examination in patients undergoing capsule endoscopy. Intern Med 2012;51:997-1001.

24. Westerhof J, Weersma RK, Koornstra JJ. Risk factors for incomplete small-bowel capsule endoscopy. Gastrointest Endosc 2009;69:74-80.

25. Buscaglia JM, Kapoor S, Clarke JO, et al. Enhanced diagnostic yield with prolonged small bowel transit time 
during capsule endoscopy. Int J Med Sci 2008;5:303-8.

26. Girelli CM, Soncini M, Rondonotti E. Implications of small-bowel transit time in the detection rate of

Cite this article as: $\mathrm{Wu} \mathrm{J}$, Ye Z, Xue A, Huang Y. Can domperidone decrease transit time of pediatric video capsule endoscopy? A randomized controlled trial. Transl Pediatr 2021;10(2):344-349. doi: 10.21037/tp-20-273 capsule endoscopy: A multivariable multicenter study of patients with obscure gastrointestinal bleeding. World J Gastroenterol 2017;23:697-702. 